\title{
Podcasts: características nas produções de professores em formação continuada ${ }^{1}$
}

\author{
Podcasts: traces in in-service teachers' productions
}

\author{
Vera Lúcia Lopes Cristovão \\ Universidade Estadual de Londrina \\ Vinicius Neves de Cabral ${ }^{2}$ \\ Universidade Estadual de Londrina
}

Resumo

A globalização proporcionou uma extensa variedade de ferramentas tecnológicas que podem ser parte do processo de ensino / aprendizagem de uma língua estrangeira, entre elas, a mídia em foco neste trabalho, os podcasts. Pesquisas recentes têm celebrado essa mídia como um excelente recurso para professores com o objetivo supracitado (MEDEIROS, 2006; SOUZA; MARTINS, 2007; UCHOA, 2010). Neste trabalho, que faz parte de um projeto maior intitulado "O uso de podcasts na educação continuada de professores de língua inglesa", apresentamos a análise dos podcasts produzidos por professores em formação continuada durante um curso projetado para dar suporte aos professores com algumas ferramentas tecnológicas digitais emergentes. Em primeiro lugar, apresentamos nosso referencial teórico-metodológico, baseado principalmente no Interacionismo Sociodiscursivo (ISD). Em seguida, trazemos a discussão dos resultados, que aponta que o ensino com base em gêneros textuais proposto pelo ISD alcançou seu objetivo, o de preparar os professores para que possam utilizar a ferramenta podcast com propriedade e destreza. Os resultados também apontam que alguns dos professores ainda precisam melhorar suas habilidades de produção oral para trabalhar com mídias e gêneros textuais orais. Além disso, chegamos à conclusão de que o uso de tecnologias emergentes ainda precisa vencer algumas barreiras.

Palavras-chave

Gêneros textuais, Educação de professores, Formação continuada, Podcast. 


\section{Abstract}

The new globalized world provides a wide variety of technological tools that could be part of the teaching/learning process of a foreign language. Those include the media focused in this paper, the podcasts. Recent researches have been celebrating these media as a great resource to teachers (MEDEIROS, 2006; SOUZA; MARTINS, 2007; UCHÔA, 2010). In this paper, which is part of a wider project called "The use of podcast in continuing education of English teachers", we present an analysis of the podcasts produced by in-service teachers during a course designed to scaffold teachers with some new technological tools. We first present our theoreticalmethodological approach mainly based on the Social-Discoursive Interactionism (SDI), then we present the discussion of the results, which have demonstrated that the genre-based approach proposed by SDI has achieved its purpose in the course: preparing teachers to successfully use the media in discussion. However, we have unfortunately found that some of the teachers still need improvement regarding their oral production skills in order to work with oral media and text genres. Besides that, we are aware that the use of technology in class still has got some barriers to overcome.

\section{Keywords}

Genres, Teacher education, Continued education, Podcast. 


\section{Introdução}

Quando voltamos nossos olhos para o passado, percebemos que durante a breve história do "homo sapiens" diferentes revoluções têm ocorrido. Indubitavelmente, podemos afirmar que vivemos na era da Revolução Tecnológica, pois, segundo os dados da Folha de São Paulo (SAMPAIO, 2012), mais de 78 milhões de brasileiros estão conectados à internet por meio de computadores, laptops, tablets, celulares e roteadores, representando um crescimento de quase $600 \% \mathrm{em}$ relação a 2009. Ao observar o mundo a nossa volta, é difícil imaginar a sociedade atual sem toda a "parafernália" tecnológica e a internet. Muito desses aparatos se tornaram itens de primeira necessidade e, por isso, são tão indispensáveis quanto água e energia elétrica, por exemplo.

De acordo com Leffa (2001), essa situação reflete-se nas salas de aula, uma vez que a escola não funciona como uma célula isolada da sociedade. Pelo contrário, as revoluções ocorridas na sociedade são vividas por diretores, professores e alunos, fundamentando a necessidade de um processo de formação de professores, e não apenas de treinamento desses profissionais.

Esta pesquisa justifica-se devido à necessidade de domínio de ferramentas tecnológicas digitais por professores em exercício nas redes municipais e estaduais de ensino do Núcleo Regional de Educação de uma cidade do interior do norte do Paraná.

Os dados foram gerados dentro de um curso de formação continuada promovido pelo projeto "Novos Talentos", financiado pela CAPES, ${ }^{3}$ no qual nos propomos a trabalhar possíveis usos de tecnologias no ensino e na produção de materiais que explorem recursos tecnológicos para seus contextos didáticos. Dentro desses limites, nesta pesquisa, investigamos a aprendizagem pelos professores do curso sobre a mídia digital em foco, por meio da descrição e avaliação de suas produções. Além disso, identificamos as relações entre a intervenção e os podcasts dos professores em formação continuada, utilizando como aporte teórico-metodológico as lentes do Interacionismo Sociodiscursivo (BRONCKART, 2009). 
Neste trabalho apresentamos, em primeiro lugar, nosso referencial teórico organizado como visto na FIG. 1.

\section{FIGURA 1}

Estrutura do Artigo

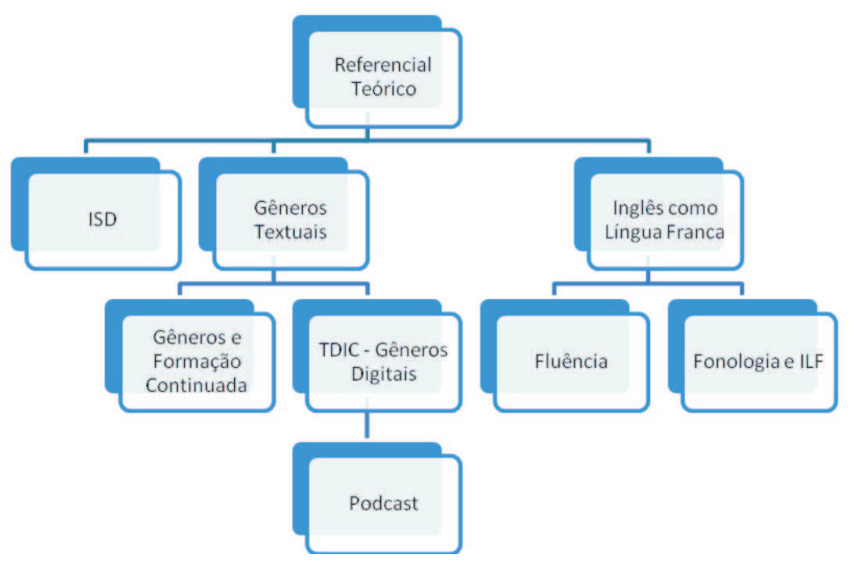

Em seguida, apresentamos nossos procedimentos metodológicos, seguidos da discussão dos resultados, procurando responder as três perguntas que permeiam este trabalho. Depois disso, apontamos nossas considerações finais, seguidas das referências bibliográficas citadas ao longo do artigo.

\section{Fundamentação Teórica}

A palavra Theoria, que significa a visão, surge no grego a partir de Theos, aquele que vê. Portanto, dentro da esfera acadêmica, poderíamos chamar de teoria as lentes usadas para análise de um objeto de estudo. Neste trabalho, para a análise do conjunto de dados, utilizamos as lentes do Interacionismo Sociodiscursivo (ISD). Nesta seção, apontamos os conceitos-chave do ISD para nossa pesquisa e destacamos a importância dos gêneros textuais digitais, da formação continuada, da mídia podcast, além de discutirmos sucintamente acerca do status atual da Língua Inglesa (LI) como uma Língua Franca (LF). 


\subsection{As lentes do Interacionismo Sociodiscursivo}

As bases e os pilares que constituem o ISD foram construídos por um grupo de pesquisadores da Universidade de Genebra, entre eles Jean-Paul Bronckart e Bernard Schneuwly, a partir da década de 80 . No processo de construção e consolidação do ISD, foram usadas diferentes bases epistemológicas, buscando referências na psicologia, na linguística, na filosofia e em outras áreas, as quais formam o que Bronckart (2006) chama de "uma ciência do humano". Assim, seus procedimentos teórico-metodológicos estão espalhados por todo o mundo em busca de expansão de conceitos e do escopo investigativo.

Grande parte da base psicológica do ISD advém dos estudos do russo Lev Vygotsky, que vê o ser humano como um ser que se constitui socialmente, tanto filo quanto ontogeneticamente (BRONCKART, 2006; 2008). Partindo desses pressupostos, emerge o questionamento central do estudo em questão: o conceito de linguagem.

Para Bronckart, a linguagem é essencial para o ser humano, uma vez que ela possibilita a organização da sociedade, assim como a regulação das atividades humanas (BRONCKART, 2006). Além disso, a visão de Bronckart se entretece com a de Coseriu, como atividade significante que ganha forma em cinco asserções: a primeira diz respeito ao caráter dialógico da linguagem, uma atividade linguageira, hoje e aqui, construída sócio-historicamente e sempre ligada a enunciados anteriores e futuros; a segunda afere a existência de línguas naturais que concretizam a linguagem, como o português, o alemão, o inglês etc.; a terceira diz respeito à instabilidade da língua, ou seja, essas línguas naturais estão em constante mudança e o que determina essa mudança é, mais uma vez, o contexto; a quarta asserção refere-se à necessidade da linguagem na construção de pensamento / conhecimento; e, finalmente, vemos a linguagem como representação do $E u$, de modo que o que o outro fala ou pensa sobre mim reforça ou não o meu eu, em outras palavras, é uma projeção do eu para e pelo outro (BRONCKART, 2008).

A partir da linguagem como organizadora das atividades humanas, elencamos as categorias de análise de textos utilizadas pelo ISD. Bronckart considera o contexto como sendo a primeira categoria a ser utilizada quando os dados estão gerados e textos (orais ou escritos) selecionados. Entretanto, com um olhar mais detalhado e profundo no texto, fazendo uso de categorias para análise, pode-se elencar e construir novas interpretações, sendo a primeira, a dos tipos de discurso. 
Para o quadro do ISD, os tipos de discurso se dividem em dois eixos: do expor e do narrar, cada qual com suas características que definem se são implicados ou autônomos. Como anteriormente levantado, os tipos de discurso não podem ser identificados, a não ser por meio de marcas linguísticas (BRONCKART, 2006).

Com base em Adam (1992, apud BRONCKART, 2009), Bronckart faz uso das sequências narrativas (objetivo de narrar algo ao destinatário), descritivas (objetivo de fazer o destinatário ver), argumentativas (objetivo de convencer), explicativas (objetivo de regular a interação) e a dialogais (função de regular a interação entre os sujeitos), além de criar uma última sequência, a injuntiva (objetivo de fazer agir o destinatário) (MACHADO, 2005).

Em uma perspectiva mais didática para essas categorias já elencadas, utilizamos as capacidades de linguagem, que são instrumentos utilizados pelo sujeito em determinadas interações linguageiras (DOLZ; SCHNEUWLY, 2004). Elas funcionam em conjunto e de forma articulada, possibilitando uma comunicação inteligível entre os sujeitos. Nós as utilizamos como propostas pelo ISD (BRONCKART, 2009), sendo elas capacidades de ação (CA), capacidades discursivas (CD) e capacidades linguístico-discursivas (CLD) e com a proposta de Cristovão e Stutz (2011), capacidades de significação (CS).

Para uma melhor compreensão da importância e significado de cada uma delas, a seguir caracterizamos as quatro capacidades, obedecendo a uma ordem de macro para microcontextos:

Capacidades de Significação relacionam-se à possibilidade criada e oferecida ao sujeito, de construir/entender práticas sociais que o envolvem;

Capacidades de Ação referem-se à construção de representações e conhecimentos sobre o contexto sócio-histórico de produção do texto;

Capacidades Discursivas estão relacionadas às representações e conhecimentos no nível organizacional do texto;

Capacidades Linguístico-Discursivas estão relacionadas aos aspectos léxico-gramaticais, coesão verbal e nominal, coerência etc.

Essas capacidades de linguagem poderão ser trabalhadas / desenvolvidas por meio de uma sequência didática, que, por sua vez, é um conjunto de atividades que visam "dar acesso aos alunos a práticas de linguagem novas ou dificilmente domináveis" (DOLZ; SCHNEUWLY, 2004). Uma sequência didática é composta 
por uma produção inicial, que tem como objetivo analisar as dificuldades e potencialidades dos alunos, de forma a regular a sequência didática e suas atividades, que serão organizadas em módulos até que se possa atingir a produção final.

Essa sequência didática será construída em torno de um gênero textual específico, uma vez que, para o ISD, os seres humanos se adaptam a determinadas situações de comunicação nas quais serão aplicados os gêneros e as capacidades de linguagem necessárias.

A próxima seção tem como foco os gêneros textuais, devido a sua importância para o ISD.

\subsection{Gêneros Textuais}

Uma das bases do ISD são os trabalhos dos filósofos russos Michael Bakhtin e Valentin Volochinov, que asseveram que o ser humano age por meio da linguagem. Assim, as atividades humanas estão sempre ligadas a sistemas semióticos, a diferentes formas de linguagem (BAKHTIN, 1997) e, para Bronckart (2006, p. 122), "a atividade de linguagem se realiza concretamente sob a forma de textos, que são unidades semióticas e comunicativas contextualizadas"; em outras palavras, só é possível agir socialmente quando o sujeito se apropria de um arcabouço de diferentes gêneros textuais (doravante, GTs).

Esses GTs são passíveis de mudanças constantes, uma vez que eles sempre se adaptarão ao seu contexto sócio-histórico de produção. Dessa forma, é o tempo, o local de produção e as situações de comunicação que irão determinar o apogeu e o declínio dos GTs. Assim, cada época e lugar tem seu conjunto de gêneros sobressalentes e, com o passar do tempo, os GTs se adaptam e ganham novas características e novos propósitos.

Os gêneros existem para organizar as tarefas do cotidiano e possibilitar / mediar a comunicação oral e escrita entre os falantes, ou como os chama Bronckart, os enunciadores. De acordo com Marcuschi (2008), só podemos nos comunicar por meio dos GTs. Assim, esse formato relativamente estável dos gêneros impede que eles sejam organizados dentro de tabelas e regras estritamente definidas, ou seja, não são estruturas rígidas, ao contrário, são flexíveis (BAKHTIN, 1997; BRONCKART, 2009; MARCUSCHI, 2008).

Na seção seguinte, abordamos a relação formação continuada, gêneros e escola. 


\subsection{A formação continuada}

Professores recém-formados, ao deixar os muros da universidade para enfrentar as salas de aula, são pressionados pela sociedade a desempenhar seus papéis sociais de modo satisfatório. Pressupõe-se que seu conhecimento teóricometodológico e sua experiência de estágio sejam de grande valia em seus primeiros anos como professor. Contudo, embora o tempo e a experiência possam fazer deste um professor cada vez melhor, é o constante contato com a universidade que pode levá-lo a uma reflexão crítica contínua acerca de suas práticas pedagógicas, de forma a manter-se sempre atualizado em relação às mudanças que ocorrem nos processos de ensino / aprendizagem de LI (LEFFA, 2001).

Atualmente, no campo da Linguística Aplicada, duas visões de formação continuada estão em jogo. A visão mais recorrente, porém não a mais aceita, é a da universidade como provedora do saber, do conhecimento, das melhores práticas pedagógicas, bem como aquela que aperfeiçoa e atualiza professores com técnicas prontas para ser aplicadas. Apesar de ter imperado durante muito tempo, a ideia de um treinamento de professores por uma universidade detentora de conhecimento vem perdendo espaço para a visão de formação continuada, que foca no pensamento reflexivo do professor sobre suas práticas e a troca de conhecimento entre universidade-escola (ARAÚJO, 2003; MEDRADO, 2003; HEBERLE, 2003).

Corroboramos com a visão de Moita-Lopes (1996), que afirma que um curso de formação deve embasar-se em conhecimentos teórico-críticos, de forma a ser capaz de desenvolver nos (futuros) professores capacidades de pensar, criticar e melhorar sua própria prática de ensino. Não consideramos que seja simples o desenvolvimento de um curso com as características descritas acima, visto que as representações construídas sócio-historicamente acerca da universidade são fortes.

Devido a constantes exigências feitas por governos e pela sociedade, muitos professores procuram os cursos de atualização nas universidades. Essas exigências, entretanto, criam dois tipos de professores em formação continuada: aqueles interessados em montar uma coleção de certificados e outros que se preocupam em atualizar seus conhecimentos e discutir novas práticas de ensino e, assim, construir uma melhor identidade profissional (HENTZ, 2003), confirmando e enfatizando a importância da segunda visão. 


\subsection{Os gêneros digitais e formação continuada}

Como previamente discutido, os GTs estão em constante mudança e desenvolvimento. Assim, com o passar do tempo, determinados gêneros vão perdendo algumas características e ganhando novas, como forma de adaptação às novas atividades linguageiras.

Muitas dessas adaptações dos gêneros vieram com a Revolução Tecnológica, que criou uma geração alunos chamados de "nativos digitais" (PRENSKY, 2006). Esses alunos assumem seus lugares nas escolas esperando, mesmo que inconscientemente, trocar com os professores informações essenciais para a sua formação tanto profissional quanto cultural.

Quando as informações trocadas com os professores são distintas das esperadas pelos alunos, o ensino se torna insatisfatório para o aluno e para o professor. Todos os dias esses nativos digitais entram em contato com diferentes ferramentas tecnológicas que possibilitam seu aprendizado e sua diversão (PRENSKY, 2006). Esses alunos, porém, precisam pensar criticamente em meio às milhares de informações encontradas pelo caminho; nessa função de promover espaços críticos e ferramentas para esse agir entra a responsabilidade do professor (FERREIRA, 2011).

Além disso, a ocorrência de interações culturais e sociais realizadas por meio de instrumentos digitais cresce a cada dia (BRAGA, 2010; FERREIRA, 2011). É parte da tarefa do professor capacitar seu aluno a usar essas ferramentas e as cadeias de gêneros (DEVITT, 2009) que as envolvem, de forma efetiva. Em outras palavras, ajudar os nativos digitais a usar a linguagem como forma de ação social.

O trabalho com as Tecnologias Digitais de Informação e Comunicação (TDICs) já não é mais uma opção, mas uma obrigação devido a razões anteriormente elencadas (FERREIRA, 2011).

\subsection{Uma mídia em desenvolvimento}

O podcast, apesar de ser ainda desconhecido por muitos, vem ganhando espaço, desde 2004 quando Adam Curry, o podfather, produziu seu primeiro arquivo (GODWIN-JONES, 2005; SOUZA; MARTINS, 2007; MEDEIROS, 2006). O termo podcast é a junção das palavras "iPod", um aparelho usado para tocar arquivos de formato MP3, e a palavra "broadcasting", que significa 'transmissão'. A ferramenta é um arquivo de áudio MP3 que pode ser acessado direta- 
mente na web e, às vezes, é disponibilizado para ser baixado em uma mídia digital (computador, tablet, smartphone etc.). O uso dessa ferramenta varia entre diversão, informação, aprendizagem etc. Hoje, a ferramenta está presente nos mais diferentes sites da Web - por exemplo, em grandes jornais como o The New York Times,${ }^{4}$ que utiliza essa ferramenta para disponibilizar aos leitores uma alternativa de acesso às informações locais e mundiais.

Além de ser utilizado na difusão de informações, opiniões, críticas, entre outras coisas, o podcast vem sendo amplamente utilizado no aprendizado de línguas estrangeiras (CARVALHO et. al., 2008). Grandes organizações como a $\mathrm{BBC}^{5}$ e a Deutsche Welle, ${ }^{6}$ disponibilizam áudios em MP3 para download para praticamente todos os níveis de aprendizagem. Esse aumento no uso desses arquivos no ensino / aprendizagem de línguas estrangeiras despertou o interesse de vários pesquisadores nos últimos anos (MEDEIROS, 2006; SOUZA; MARTINS, 2007; UCHÔA, 2010), que procuraram e procuram saber como e quão efetiva essa ferramenta pode ser.

Apesar de frequentemente encontrarmos os podcasts como gêneros textuais, fazemos aqui uma ressalva convergente com Bonini (2011), ao considerarmos o podcast como mídia e não como gênero textual. Corroboramos o autor que diz que a mídia é fonte de variado número de gêneros e seria um "elemento essencial” para sua veiculação. Assim, o arquivo MP3 seria o suporte da mídia, como a materialidade dela, e a internet uma hipermídia. Em conclusão, o podcast é uma mídia, sustentada por seu suporte MP3, que pode carregar em si uma cadeia de gêneros, e que será, por fim, disponibilizada na hipermídia Web 2.0.

A classificação dos podcasts coletados foi feita com base em Medeiros (2006) e Carvalho et. al. (2008) com algumas ressalvas. Medeiros (2006) os classifica em quatro tipos principais de acordo com seu objetivo. São eles: a metáfora; editado; registro e os educacionais.

O primeiro deles é o "metáfora", modelo que se parece muito com os programas de rádio. O segundo é o "editado", que seria um podcast com o conteúdo de um programa que já foi ao ar, mas que foi disponibilizado na rede para aqueles que não tiveram a oportunidade de ouvi-lo. Os do tipo "registro" são os mais variados em conteúdo, pois assumem características de audioblogs. Por último, são os podcasts chamados de educacionais, que recebem essa nomenclatura por transmitirem aulas, cursos etc., aos seus ouvintes. Esse modelo de podcast é o que mais nos interessa neste estudo.

Classificamos todos os nossos arquivos como educacionais, pois, apesar de alguns deles não serem aulas ou cursos, eles trabalham com assuntos de inte- 
resse de alunos e professores. De acordo com Carvalho et. al. (2008), podcasts podem ser classificados de acordo com a TAB. 1 de "Taxonomia de Podcasts".

\section{TABELA 1}

Categorias Taxonômicas Carvalho et al. (2008)

\begin{tabular}{|c|c|c|c|c|c|}
\hline TIPO & FORMATO & DURAÇĀO & AUTOR & ESTILO & FINALIDADE \\
\hline $\begin{array}{l}\text { Expositivo/ informativo } \\
\text { (anailise; resumo; sintese; } \\
\text { excerto de textos; poemas; } \\
\text { casos; explicaçồ des } \\
\text { conceitos ou principios ou } \\
\text { fenômenos; descriçào do } \\
\text { funcionamento } \\
\text { ferramentas de } \\
\text { equipamentos } \\
\text { software...). }\end{array}$ & \multirow[t]{4}{*}{$\begin{array}{l}\text { Áudio } \\
\text { Video } \\
\text { - Vodeast } \\
\text {-Screencast } \\
\text { Captura de } \\
\text { ecrà com } \\
\text { locuçào } \\
\text { Enhanced } \\
\text { Podeast } \\
\text { Combinaçào } \\
\text { de imagem } \\
\text { com locuçăo }\end{array}$} & \multirow[t]{4}{*}{$\begin{array}{l}\text { Curto = } \\
1^{\prime}-55^{\prime} \\
\text { Mederade= } \\
6^{\prime}-15^{\prime} \\
\text { Lengo }= \\
+15^{\prime}\end{array}$} & \multirow[t]{4}{*}{$\begin{array}{l}\text { Professor } \\
\text { Aluno (s) } \\
\text { Outro Jornalista, } \\
\text { cientista, politico. } \\
\text { etc. }\end{array}$} & \multirow[t]{4}{*}{$\begin{array}{l}\text { Formal } \\
\text { Informal }\end{array}$} & \multirow[t]{4}{*}{$\begin{array}{l}\text { Informar } \\
\text { Motivar' } \\
\text { sensibilizar } \\
\text { Incentivar a } \\
\text { questionar (...) }\end{array}$} \\
\hline $\begin{array}{l}\text { Feedback/ comentários a } \\
\text { trabalhos dos Alunos }\end{array}$ & & & & & \\
\hline $\begin{array}{l}\text { Instruçôes recomendaçôes } \\
\text { (indicaç̋̄es plou } \\
\text { procedimentos para } \\
\text { realizaçẫo de trabalhos } \\
\text { práticos; orientaçồ des } \\
\text { estudo; recomendacôes) }\end{array}$ & & & & & \\
\hline $\begin{array}{l}\text { Materiais autènticos } \\
\text { (Materiais criados para o } \\
\text { público em geral e nalo } \\
\text { especificamente para um } \\
\text { determinado curso ou para } \\
\text { estudantes, tais como } \\
\text { entrovistas. poticias, } \\
\text { programas de rádio, ete.). }\end{array}$ & & & & & \\
\hline
\end{tabular}

Como apresentado na TAB. 1, para Carvalho et. al. (2008), existem seis níveis para classificação de podcasts. Entretanto, em nossa pesquisa, algumas das características apontadas pelos autores não se fazem necessárias. A seguir justificamos as adaptações aplicadas neste trabalho.

O primeiro nível seria o "tipo" do podcast, que se divide em quatro, dependendo das características assumidas. O segundo nível é o "formato". Esse nível de análise não se faz necessário em nossa pesquisa, uma vez que todos os podcasts coletados são apenas áudio e não vodcasts ou "enhanced podcasts". Apesar de nenhum dos podcasts coletados ter duração superior a cinco minutos, esse nível de análise foi essencial para evidenciar o efeito da abordagem do professor 
e do material em sala. O nível "autor", bem como o "formato", foi retirado da análise, já que todos os participantes do curso eram professores em formação continuada. O quinto nível é "estilo", que pode variar entre formal e informal e, por último, a finalidade, que pode ser de informar, divulgar, motivar etc.

Além de nos preocuparmos com o nível organizacional dos podcast, $\mathrm{o}$ nível fonológico da língua recebe agora especial atenção, uma vez que estamos tratando de uma mídia oral, na qual as habilidades fonológicas do enunciador têm um papel fundamental na compreensão do interlocutor. Por isso, tratamos nas próximas seções, das discussões em relação ao status da LI como uma Língua Franca (ELF - English as a Língua Franca), e, em seguida, nos atentamos ao significado de fluência, os aspectos fonológicos da LI e sua importância.

\subsection{O status do inglês como Língua Franca (ILF)}

Nas últimas décadas, observa-se o surgimento de uma preocupação no mundo da Linguística Aplicada que atraiu e atrai uma grande quantidade de pesquisadores: o Inglês como uma Língua Franca (LF) (JENKIS, 2006; BAKER, 2009; SIFAKIS, 2007; LLURDA, 2004; RAJAGOPALAN, 2003). A LI é, hoje, considerada uma LF, pois existe um número maior de falantes não nativos do que nativos. Estudiosos têm se debruçado sobre a questão da expansão da LI, uma vez que esse uso atual sem precedentes causa mudanças na língua, refletindo no processo de ensino / aprendizagem, principalmente nos países ditos do círculo em expansão (JENKINS, 2006), ou seja, países nos quais a LI é compreendida como língua estrangeira.

A formação inicial e continuada de professores de LI começa a tomar moldes diferentes dos que haviam sido praticados até o momento e a importância de determinados aspectos, por exemplo, a luta diária para alcançar um sotaque chamado de "nativo", é deixada em segundo plano. Entretanto, Sifakis (2007) aponta que, na maioria das escolas de idiomas dos países do círculo em expansão, uma das variedades consideradas como padrão, inglês britânico e americano, ainda é o foco.

Seidlhofer (2004) afere que "professores de inglês precisam entender as implicações de uma expansão da língua sem precedentes e as complexas decisões as quais lhes serão requisitadas" (tradução nossa) ${ }^{7}$. Jenkins (1998) considera que o ensino de aspectos de "connected speech" (explicaremos mais adiante) pode não ajudar em nada o aprendiz, uma vez que eles são naturais em falantes nativos, mas não em aprendizes do círculo em expansão. Por isso, Schmitz (2012) aponta 
que o ILF traz apenas mais responsabilidades e demanda mais atenção, diligência e trabalho do professor de LI e não menos, uma vez que sempre haverá alunos interessados em atingir um nível de fluência e proficiência o mais perto possível do chamado nativo.

Adotamos aqui as preocupações de Jenkins $(2006,2007)$ de não vermos o objetivo dos estudos como defensores de um único inglês para o mundo. Além disso, ressaltamos que esses estudos não devem ser usados como justificativa para a falta de proficiência na língua. $\mathrm{O}$ estudo de uma língua estrangeira deve procurar tornar o falante o mais inteligível possível, evitando problemas de comunicação futuros. Concordamos também que existem variedades linguísticas, mas existem também erros. Desse modo, alunos de LI devem estar sempre atentos e entender que não mais existe a necessidade de atingir um sotaque de um "nativo", mas devem procurar melhorar suas habilidades a ponto de serem capazes de se fazer entender por qualquer falante de qualquer um dos círculos. Em conformidade com essas razões, buscamos na literatura o conceito e a importância de fluência, apresentado a seguir.

\subsubsection{Fluência}

Para Fillmore (1979, apud BROWN, 2003), o sujeito precisa ser dotado de quatro habilidades para ser considerado fluente em determinada língua. São elas:

1. ser capaz de preencher suas pausas com fala;

2. ser capaz de falar usando sentenças coerentes e semanticamente densas;

3. ser capaz de expressar-se em relação a uma grande variedade de assuntos; e

4. ser criativo e imaginativo usando a língua" (tradução nossa).

Apesar de concordarmos com a perspectiva de Fillmore (1979), acreditamos que o falante deve ser capaz de usar aspectos fonológicos e léxico-gramaticais sem problemas facilmente perceptíveis, assim como seguir determinadas regras. Para Cameron (2002), essas regras não são apenas gramaticais mas também de socialização e relação com outras pessoas, ou seja, significam adequar-se ao contexto sócio-histórico de comunicação.

\subsubsection{Fonologia da Língua Inglesa}

Damos especial atenção às análises fonológicas, uma vez que elas são molas propulsoras para a compreensão e fluência, de acordo com o Common Eu- 
ropean Framework (2001). Segundo Halliday (2004, p.11), "se quisermos ter uma dimensão / visão detalhada da língua, é essencial que primeiro se faça uma excursão pela fonologia". Apesar do ensino / aprendizagem de fonologia de LI ser extenso e denso, fazemos um recorte e nos debruçamos apenas sobre estudos relacionados ao "connected speech".

Quando produzem textos orais em LI, falantes nativos e os falantes proficientes / fluentes não pronunciam cada palavra isoladamente, mas procuram reduzir o número de movimentos, muitas vezes reduzindo também a compreensão de falantes ainda não preparados para a união de sons e a redução de fonemas que ocorre durante o "connected speech".

No aspecto fonológico enfocado, observamos quatro tipos diferentes de produção de sons: assimilação, inclusão, ligação e elisão. De acordo com dados da $B B C$ Learning English ${ }^{8}$, a assimilação ocorre quando a última palavra e a palavra a seguir terminam em consoantes, alguns fonemas perderão seu som e ganharão o som da consoante da segunda palavra. No caso da inclusão, temos a possível produção extra dos fonemas $/ \mathrm{r} /, / \mathrm{w} / \mathrm{e} / \mathrm{j} /$ quando ocorre o encontro de duas vogais. Quando ocorre o encontro de uma consoante e uma vogal, chamamos de ligação. Finalmente, a elisão é o desaparecimento dos fonemas /t/ ou /d/ quando no final de uma palavra; e esses se encontram com outros determinados fonemas.

Como anteriormente colocado, para Jenkins (1998), o ensino desses aspectos pode ser desnecessário, entretanto, devemos considerar que estamos analisando uma mídia oral disponibilizada para falantes dos três círculos e que essas são produções de professores de LI.

Apresentamos até aqui nosso arcabouço teórico. A próxima seção traz nossas bases metodológicas.

\section{Procedimentos Metodológicos}

O curso de formação continuada foi realizado nas terceira e quarta semanas de julho de 2011, com duração de oito horas diárias, de segunda à sextafeira, o que perfez 40 horas. Os professores foram recebidos em uma sala de informática com um computador para cada um, com acesso aos pacotes básicos de edição de textos e áudios, assim como acesso à internet.

A geração dos dados ocorreu no segundo dia do curso quando foi utilizada a mídia podcast. A fim de obter um diagnóstico dos conhecimentos prévios dos professores, eles produziram a sua primeira versão de podcast sem nenhuma 
instrução de como ou o que ele era, ou qual estratégia deveria utilizar. Para essa produção, eles poderiam escolher entre dois assuntos (perguntas-tema), poderiam gravar um podcast como uma aula-guia sobre gêneros digitais para outros professores, ou poderiam usar características de audioblogs e um tópico polêmico que envolvesse o ensino / aprendizagem de LI.

Uma vez feita a gravação da versão de diagnóstico em um dispositivo MP4, o professor-formador realizou a intervenção. Nesse processo foram expostas aos professores em formação as características do podcast, assim como alguns exemplos de arquivos que já haviam sido disponibilizados on-line. A preparação e a gravação da segunda versão ocorreu logo após a intervenção e, diferentemente da primeira, foi acompanhada pelo professor-formador.

Como uma das características do podcast é ser um arquivo MP3 disponibilizado on-line, não faria sentido produzi-los se não fossem disponibilizados. Para isso, cada dupla de professores abriu uma conta em um reconhecido site de podcasts, o Podomatic, ${ }^{9}$ e disponibilizou seu arquivo para o mundo.

Infelizmente, nem todos os professores participantes do curso prepararam as duas versões. Assim, coletamos somente os podcasts das duplas que haviam completado as duas etapas. Desse modo, ao todo foram coletados 14 podcasts, incluindo primeira e segunda versão, ou seja, sete podcasts da primeira versão e sete da segunda.

Os podcasts foram, primeiramente, transcritos e analisados com base nas características elencadas por Carvalho et. al. (2008) e Medeiros (2006).

Após completarmos essa etapa, passamos para a análise à luz do ISD. Fizemos o Plano Textual Global de cada um dos 14 podcasts para que pudéssemos analisar sua organização textual, já que isso ajuda a confirmar ou refutar a análise anterior. Feito o Plano Textual Global (PTG), utilizamos os tipos de discurso (TD) e os tipos de sequência (TS) elencados por Bronckart (2009). Esses três procedimentos (PTG, TD e TS) fazem parte do nível organizacional, responsável por evidenciar características de configuração dos textos produzidos para essa mídia.

Para as mudanças ocorridas da primeira para a segunda versão, criamos os seguintes níveis de análise:

i. adequações preliminares: quando as alterações ocorrem somente em nível organizacional e, tanto a primeira quanto a segunda versão apresentam introdução, desenvolvimento e conclusão;

ii. adequações consideráveis: quando as alterações ocorrem somente em nível organizacional, contudo a primeira versão não possui um dos três níveis de organização de conteúdo. 
iii. adequações de grandes proporções: quando as alterações ocorrem tanto no nível organizacional quanto no conteúdo; entretanto, o assunto do podcast é mantido; e

iv. adequações severas: as alterações começam com a escolha de outro assunto, ou pergunta-tema. Essa mudança altera todo o podcast, em outras palavras, os produtores criam um outro podcast.

Para a caracterização desta mídia em relação ao nível fonológico, como apresentado anteriormente, utilizamos o Quadro Europeu Comum de Referência para as Línguas como nas características da TAB. 2.

\section{TABELA 2}

\section{Quadro Europeu Comum de Referência para as Línguas}

\begin{tabular}{|c|c|}
\hline Nivel & Controle Fonológico \\
\hline $\mathrm{C} 2$ & Como Cl \\
\hline $\mathrm{C} 1$ & $\begin{array}{l}\text { Pode variar entonação e caracterizar a tônica das sentenças corretamente } \\
\text { para expressar melhores tons de significado. }\end{array}$ \\
\hline B2 & Atingiu nivel claro e natural de pronuncia e entonação. \\
\hline B1 & $\begin{array}{l}\text { Pronúncia é geralmente clara, mesmo quando um sotaque estrangeiro é } \\
\text { evidente e ocasionalmente problemas de pronúncia ocorrem. }\end{array}$ \\
\hline A2 & $\begin{array}{l}\text { Pronúncia é geralmente clara o suficiente para ser entendida, apesar de } \\
\text { notar-se claramente um sotaque estrangeiro. Entretanto, os interlocutores } \\
\text { precisam pedir esclarecimentos em algumas ocasiões. }\end{array}$ \\
\hline Al & $\begin{array}{l}\text { Pronúncia faz parte de um repertório limitado de palavras e frases que } \\
\text { podem ser entendidas com algum esforço de nativos acostumados a lidar com } \\
\text { falantes de sua própria língua. }\end{array}$ \\
\hline
\end{tabular}

(tradução nossa)

A seguir caracterizamos os podcasts coletados na geração de dados e passamos à discussão dos resultados. 


\section{Resultados e discussão}

\subsection{A descrição}

Na TAB. 3, apresentamos a classificação dos podcasts da primeira versão conforme apresentado acima. Os títulos apresentados na tabela a seguir foram por nós sugeridos, para facilitar a sua análise, uma vez que os professores não o fizeram.

\section{TABELA 3}

Descrição dos podcasts com base em

Carvalho et. al. (2008)

\begin{tabular}{|c|c|c|c|c|}
\hline NOME & TाFO & DURACAO & ESTILO & FINALIDADE \\
\hline $\begin{array}{l}\text { "Blog - movie } \\
\text { and literature" }\end{array}$ & $\begin{array}{l}\text { Expositivo/ } \\
\text { Informativo }\end{array}$ & $0 \cdot 51$ & Formal & Divul gar o blog criado pelas autoras. \\
\hline $\begin{array}{l}\text { "Bullying in our } \\
\text { society" }\end{array}$ & $\begin{array}{l}\text { Expositivo/ } \\
\text { Informativo }\end{array}$ & $0 \cdot 36$ & Formal & $\begin{array}{l}\text { Orientar a sociedade em genal - pais, } \\
\text { professores, alunos etc. - em relaçlo a luta } \\
\text { contra o bullying. }\end{array}$ \\
\hline $\begin{array}{l}\text { "How to } \\
\text { overcome } \\
\text { bullying?" }\end{array}$ & $\begin{array}{l}\text { Expositivo/ } \\
\text { Informativo }\end{array}$ & 1.01 & Formal & $\begin{array}{l}\text { Informar, orientar, motivar pessoas da } \\
\text { sociedude em geral a se posicionarem contra } \\
\text { o bullying. }\end{array}$ \\
\hline $\begin{array}{l}\text { Presenting a } \\
\text { Facebook Profile }\end{array}$ & $\begin{array}{l}\text { Expositivo / } \\
\text { Informativo }\end{array}$ & $1 \cdot 21$ & Formul & $\begin{array}{l}\text { Informar, divulgar as informaçōes contidas } \\
\text { em um perfil do Facebook. }\end{array}$ \\
\hline $\begin{array}{l}\text { "The problem } \\
\text { about teaching } \\
\text { "digital genres" }\end{array}$ & $\begin{array}{l}\text { Expositivo/ } \\
\text { Informativo }\end{array}$ & $0+30$ & Formal & $\begin{array}{l}\text { Questionar, criticar, problematizar questồes } \\
\text { relacionadas com o ensino de gèneros digitais } \\
\text { em escolas públicas de Londrina. }\end{array}$ \\
\hline $\begin{array}{l}\text { "Social Inclusion } \\
\text { in class" }\end{array}$ & $\begin{array}{l}\text { Expositive / } \\
\text { Informativo }\end{array}$ & $0 \div 58$ & Formal & Questionar, criticar, problematizar. \\
\hline $\begin{array}{l}\text { "Using Blogs in } \\
\text { Class" }\end{array}$ & $\begin{array}{l}\text { Expositivo / } \\
\text { Informativo }\end{array}$ & $1 \cdot 43$ & Informal & $\begin{array}{l}\text { Informar, divulgar e motivar o uso do blog } \\
\text { como um gênero interessante para a sala de } \\
\text { aula, uma vez, que ele que faz parte da vida } \\
\text { da sociedade moderna. }\end{array}$ \\
\hline
\end{tabular}

Agrupados na tabela com base em Carvalho et. al. (2008), os podcasts da primeira versão foram todos considerados do tipo Expositivo / Informativo e, provavelmente devido à falta de contato prévio com esse tipo de mídia, nenhum deles tinha mais do que dois minutos de duração. Seis deles eram de estilo formal, sendo apenas um informal. A finalidade de cada um deles varia entre questionar, 
criticar, problematizar, informar, divulgar etc., dependendo do tema e da abordagem dos produtores, sendo que três duplas escolheram a primeira pergunta-tema, três pela segunda opção e uma dupla optou mesclar as duas, produzindo um arquivo em que falavam sobre os problemas do ensino dos gêneros textuais em escolas públicas.

Para a segunda versão, como na TAB. 4, observamos mudanças de duração em todas as produções, sendo que essas mudanças são resultado de uma melhor organização do conteúdo. Entretanto, não observamos mudanças no tipo ou no estilo dos mesmos.

\section{TABELA 4}

Descrição dos podcasts com base em Carvalho et. al. (2008)

\begin{tabular}{|c|c|c|c|c|}
\hline NOME & TIPO & DURACÁO & ESTILO & FINALIDADE \\
\hline $\begin{array}{l}\text { "Blog - movie and } \\
\text { literature" } \\
\text { "Bullying in our } \\
\text { society" }\end{array}$ & $\begin{array}{l}\text { Expositivo/ } \\
\text { Informativo } \\
\text { Expositivo/ } \\
\text { Informativo }\end{array}$ & $\begin{array}{l}0.47 \\
1.40\end{array}$ & $\begin{array}{l}\text { Formal } \\
\text { Formal }\end{array}$ & $\begin{array}{l}\text { Divulgar o blog eriado pelas } \\
\text { autoras. } \\
\text { Orientar a sociedade em geral - } \\
\text { pais, professores, alunos etc.-em } \\
\text { relacão a luta contra o bullvine. }\end{array}$ \\
\hline $\begin{array}{l}\text { "How to overcome } \\
\text { bullying?" }\end{array}$ & $\begin{array}{l}\text { Expositivo/ } \\
\text { Informativo }\end{array}$ & $1 \cdot 13$ & Formal & $\begin{array}{l}\text { Informar, orientar, motivar } \\
\text { pessoas da sociedade em geral a } \\
\text { se posicionarem contra o } \\
\text { bullving. }\end{array}$ \\
\hline $\begin{array}{l}\text { "Interview } \\
\text { English for basic } \\
\text { education" } \\
\text { "The problem } \\
\text { about teaching } \\
\text { "digital genres" }\end{array}$ & $\begin{array}{l}\text { Expositivo/ } \\
\text { Informativo } \\
\text { Expositivo/ } \\
\text { Informativo }\end{array}$ & $1 \cdot 41$ & Formal & $\begin{array}{l}\text { Informar, divulgar, motivar o } \\
\text { projeto de inglés na educaçâo } \\
\text { básica. } \\
\text { Questionar, criticar, } \\
\text { problematizar questôes } \\
\text { relacionadas com o ensino de } \\
\text { géneros digitais em escolas } \\
\text { públicas de Londrina }\end{array}$ \\
\hline $\begin{array}{l}\text { "Social Inclusion in } \\
\text { class" }\end{array}$ & \begin{tabular}{|l|} 
Expositivo / \\
Informativo
\end{tabular} & $I^{\prime} 10$ & Formal & $\begin{array}{l}\text { Questionar, } \\
\text { nroblematizar. }\end{array}$ \\
\hline $\begin{array}{l}\text { "Using Blogs in } \\
\text { Class" }\end{array}$ & $\begin{array}{l}\text { Expositivo// } \\
\text { linformativo }\end{array}$ & $1 \cdot 16$ & Informal & $\begin{array}{l}\text { Informar, divulgar e motivar o } \\
\text { uso do blog como um gênero } \\
\text { interessante para a sala de aula, } \\
\text { uma vez, que ele que faz parte da } \\
\text { vida da sociedade moderna. }\end{array}$ \\
\hline
\end{tabular}

\subsection{Adequações}

Nos QUADROS 1 a 6 apresentamos as adequações ocorridas da primeira para a segunda versão dos podcasts em relação às categorias de análise utilizadas. No nível organizacional, nem todos os podcasts se organizavam de acordo 
com as categorias de Carvalho et. al. (2008), com começo, meio e fim, ou como chamamos, introdução, desenvolvimento e conclusão.

Observe nos QUADROS 1 e 2 que, na primeira versão, as autoras não se identificavam e não se posicionavam socialmente, essas adequações são certamente reflexos da intervenção, tema a ser abordado na próxima seção. Enquanto as adequações nesse podcast foram apenas preliminares, no podcast do QUADRO 3 observamos adequações consideráveis, uma vez que, na primeira versão, o podcast apresentava uma introdução falha e não possuía nenhum tipo de conclusão.

\section{QUADRO 1 \\ BLOG - MOVIE AND LITERATURE}

\begin{tabular}{|c|c|c|c|}
\hline $\begin{array}{l}\text { BLOG - } \\
\text { MOVIE AND } \\
\text { LTERATURE }\end{array}$ & $1^{\text {I" versão }}$ & $2^{a}$ versão & Adequações \\
\hline $\begin{array}{l}\text { Plano Textual } \\
\text { Global }\end{array}$ & $\begin{array}{l}\text { INTRODUÇÃO: } \\
\text { incentivo a criaçăo de um } \\
\text { blog sobre filmes e } \\
\text { literatura } \\
\text { DESENVOL VIMENTO: } \\
\text { sugeståo de atividades a } \\
\text { serem desenvolvidas em } \\
\text { sala } \\
\text { CONCLUSÃO:vantagens } \\
\text { proporcionados pelo blog. }\end{array}$ & $\begin{array}{l}\text { INTRODUÇÃO: apresentação } \\
\text { dos doisinteractantes com nome } \\
\text { e profissão. Exposição do } \\
\text { objetivo e divulgaçâo do nome } \\
\text { do blog. } \\
\text { DESENVOLVIMENTO: } \\
\text { retomada do nome do blog e o } \\
\text { que ele of erece aos professores. } \\
\text { CONCLUSÃO: convite a } \\
\text { participaçâo e sugestâo de } \\
\text { contato. }\end{array}$ & \multirow[t]{3}{*}{$\begin{array}{l}\text { Sofreu } \\
\text { adequações } \\
\text { preliminares }\end{array}$} \\
\hline $\begin{array}{l}\text { Tipos de } \\
\text { Discurso }\end{array}$ & DISCURSO TEÓRICO & $\begin{array}{l}\text { FUSÃO = DISCURSO } \\
\text { INTERATIVO + TEÓRICO }\end{array}$ & \\
\hline $\begin{array}{l}\text { Tipos de } \\
\text { Sequência }\end{array}$ & DESCRITIVA & DIALOGAL E DESCRITIVA & \\
\hline
\end{tabular}




\section{QUADRO 2 \\ HOW TO OVERCOME BULLYING}

\begin{tabular}{|c|c|c|c|}
\hline $\begin{array}{l}\text { HOW TO } \\
\text { OVERCOME } \\
\text { BULLYING }\end{array}$ & $1^{4}$ versã̃o & $2^{a}$ versão & Adequaçōes \\
\hline $\begin{array}{l}\text { Plano Textual } \\
\text { Global }\end{array}$ & $\begin{array}{l}\text { INTRODUÇÃO: } \\
\text { explanação do } \\
\text { significado de bullying e } \\
\text { como ele acontece. } \\
\text { DESENVOLVIMENTO: } \\
\text { discussã̃o e ampliaçâo do } \\
\text { tema. } \\
\text { CONCLUSÃO: } \\
\text { colocação de questôes } \\
\text { que instigam o leitor. } \\
\text { Convite à participação. }\end{array}$ & $\begin{array}{l}\text { INTRODUÇ̃̃: apresentação } \\
\text { da interactante com profissâo, } \\
\text { tambèm apresenta o tema do } \\
\text { podcast. Após apresentar o tema, } \\
\text { a interactante esclarece alguns } \\
\text { pontos importantes em relaçầo } \\
\text { ao bullying. } \\
\text { DESENVOLVIMENTO: } \\
\text { continua caracterização do } \\
\text { problema e fala da luta contra o } \\
\text { bullying. } \\
\text { CONCLUSÃO: brainstorm } \\
\text { como perguntas ainda não } \\
\text { respondidas sobre o assunto e } \\
\text { convite a participacão à causa. }\end{array}$ & $\begin{array}{l}\text { Foram feitas } \\
\text { adequações } \\
\text { preliminares. }\end{array}$ \\
\hline $\begin{array}{l}\text { Tipos de } \\
\text { Discurse }\end{array}$ & $\begin{array}{l}\text { FUSĀO = DISCURSO } \\
\text { INTERATIVO + } \\
\text { TEÓRICO }\end{array}$ & $\begin{array}{l}\text { FUSÃO = DISCURSO } \\
\text { INTERATIVO + TEÓRICO }\end{array}$ & \\
\hline $\begin{array}{l}\text { Tipos de } \\
\text { Sequência }\end{array}$ & ARGUMENTATIVA & $\begin{array}{l}\text { DIALOGAL, EXPLICATIVA e } \\
\text { ARGUMENTATIVA }\end{array}$ & \\
\hline
\end{tabular}




\section{QUADRO 3 \\ USING BLOG IN CLASS}

\begin{tabular}{|c|c|c|c|}
\hline $\begin{array}{l}\text { USING } \\
\text { BLOG IN } \\
\text { CLASS }\end{array}$ & $1^{a}$ versão & $2^{a}$ versão & Adequaçôes \\
\hline $\begin{array}{l}\text { Plano } \\
\text { Textual } \\
\text { Global }\end{array}$ & $\begin{array}{l}\text { INTRODUÇÃo colocaçăo do } \\
\text { status da internet atualmente e } \\
\text { exposição do tema a ser tratado. } \\
\text { DESENVOLVIMENTO: } \\
\text { exposiçâo das vantagens do uso } \\
\text { de blogs em sala de aula de lingua } \\
\text { inglesa. Apresentação de } \\
\text { exemplos de blogs que podem ser } \\
\text { usados pelos professores. } \\
\text { CONCLUSÃO: } \\
\text { CONCLUSÃO }\end{array}$ & 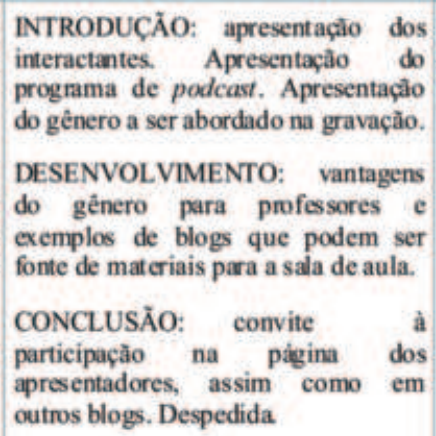 & $\begin{array}{l}\text { Foram feitas } \\
\text { adequaçōes } \\
\text { consideráveis. }\end{array}$ \\
\hline $\begin{array}{l}\text { Tipos de } \\
\text { Discurso }\end{array}$ & DISCURSO INTERATIVO & DISCURSOINTERATIVO & \\
\hline $\begin{array}{l}\text { Tipos de } \\
\text { Sequência }\end{array}$ & DESCRITIVA & DIALOGAL & \\
\hline
\end{tabular}

No podcast a seguir - QUADRO 4 - percebemos adequações de grandes proporções, percebe-se que na primeira versão o conteúdo do podcast era apenas superficial, entretanto, na segunda, houve uma melhora no conteúdo e o podcast ganhou forma e essência novas. 


\section{QUADRO 4 \\ BULLYING IN OUR SOCIETY}

\begin{tabular}{|c|c|c|c|}
\hline $\begin{array}{l}\text { BULLYING } \\
\text { IN OUR } \\
\text { SOCIETY }\end{array}$ & $1^{\text {a }}$ versâo & $2^{a}$ versão & Adequạ̧̄es \\
\hline $\begin{array}{l}\text { Plano } \\
\text { Textual } \\
\text { Global }\end{array}$ & $\begin{array}{l}\text { INTRODUCÃO: } \\
\text { colocação do tema. } \\
\text { DESENVOLVIMENTO: } \\
\text { razóes pelas quais o } \\
\text { bullying acontece. } \\
\text { CONCLUSÃO: incitaçăo } \\
\text { da tomada de consciência } \\
\text { do interlocutor. }\end{array}$ & $\begin{array}{l}\text { INTRODUÇ̃̃: posição social } \\
\text { dos apresentadores e exposiçăo } \\
\text { do problema a ser tratado no } \\
\text { podcast. Convite à luta contra a } \\
\text { violência. } \\
\text { DESENVOLVIMENTO: as } \\
\text { autoras apontam raz̄es para os } \\
\text { problemas enfrentados. Também } \\
\text { apresentam alguns exemplos de } \\
\text { violência sofrida por alunos. } \\
\text { CONCLUSÃO: para finalizar, } \\
\text { fica claro o posicionamento } \\
\text { contrírio ao bullying. Convite à } \\
\text { participação na luta contra o } \\
\text { bullying. }\end{array}$ & $\begin{array}{l}\text { Foram feitas } \\
\text { adequaçốes } \\
\text { de grandes } \\
\text { proporçōes. }\end{array}$ \\
\hline $\begin{array}{l}\text { Tipos de } \\
\text { Discurso }\end{array}$ & $\begin{array}{l}\text { FUSÃO = DISCURSO } \\
\text { INTERATIVO } \\
\text { TEÓRICO }\end{array}$ & $\begin{array}{l}\text { FUSÃO = DISCURSO } \\
\text { INTERATIVO + TEÓRICO }\end{array}$ & \\
\hline $\begin{array}{l}\text { Tipos de } \\
\text { Sequência }\end{array}$ & ARGUMENTATIVA & $\begin{array}{l}\text { EXPLICATIVA } \\
\text { ARGUMENTATIVA }\end{array}$ & \\
\hline
\end{tabular}

O único podcast que apresentou mudanças severas está no QUADRO 5. As professoras-produtoras fizeram um novo podcast após a intervenção e decidiram focar na segunda pergunta-tema. Esse tipo de mudança deixou clara a eficiência da intervenção no caso dessa dupla, mas infelizmente não garante o mesmo efeito em outras. 


\section{QUADRO 5 \\ TROCA DE ASSUNTO}

\begin{tabular}{|c|c|c|c|}
\hline $\begin{array}{l}\text { TROCA } \\
\text { DE } \\
\text { ASSUNTO }\end{array}$ & $\begin{array}{l}1^{\text {n }} \text { versão - PRESENTING A } \\
\text { FACEBOOK PROFILE }\end{array}$ & $\begin{array}{l}2^{a} \text { versão - INTERVIEW - } \\
\text { INGLĖS NA EDUCAÇẢO } \\
\text { BÄSICA }\end{array}$ & Adequaçōes \\
\hline $\begin{array}{l}\text { Plano } \\
\text { Textual } \\
\text { Global }\end{array}$ & $\begin{array}{l}\text { INTRODUÇÃO: apresentaçăo do } \\
\text { tema que será abondado no } \\
\text { podkast. } \\
\text { DESENVOLVIMENTO: } \\
\text { demonstraçầo de um "profile" do } \\
\text { Facebook. } \\
\text { CONCLUSÃO: } \\
\text { CONCLUSÃO }\end{array}$ & $\begin{array}{l}\text { INTRODUÇÕO: } \\
\text { apresentaçào do interactante, } \\
\text { do assunto do podcast e da } \\
\text { primeina entrevistada. } \\
\text { DESENVOLVIMENTO: } \\
\text { entrevista com a primeira } \\
\text { interactante, que fala de sua } \\
\text { experiência como } \\
\text { coordenadora do projeto e } \\
\text { entrevista com a segunda } \\
\text { interactante que fala de sua } \\
\text { perspectiva como professora. } \\
\text { CONCLUSÃO: finalizaçăo } \\
\text { do podcast com despedida e } \\
\text { informaçâo de contato. }\end{array}$ & $\begin{array}{l}\text { Devido à mudança } \\
\text { do assunto a ser } \\
\text { abordado, foram } \\
\text { feitas adequaçōes } \\
\text { severas mudaças } \\
\text { na organizạ̧a, na } \\
\text { estrutura As } \\
\text { professoras } \\
\begin{array}{l}\text { construiram um } \\
\text { novo podkast. }\end{array}\end{array}$ \\
\hline $\begin{array}{l}\text { Tipos de } \\
\text { Discurso }\end{array}$ & DISCURSOTEÓRICO & DISCURSO INTERATIVO & \\
\hline $\begin{array}{l}\text { Tipos de } \\
\text { Sequência }\end{array}$ & DESCRITIVA & DIALOGAL, DESCRITIVA & \\
\hline
\end{tabular}

Somente uma dupla de professores conseguiu produzir um arquivo que abarcasse as duas perguntas-tema (QUADRO 6). As adequações entre a primeira e segunda versões ocorreram em nível organizacional e no conteúdo. 


\section{QUADRO 6 \\ THE PROBLEM ABOUT TEACHING DIGITAL GENRES}

\begin{tabular}{|c|c|c|c|}
\hline $\begin{array}{l}\text { THE } \\
\text { PROBLEM } \\
\text { ABOUT } \\
\text { TEACHING } \\
\text { DIGITAL } \\
\text { GENRES }\end{array}$ & 1 'versão & $2^{a}$ versilo & Adequaçôes \\
\hline $\begin{array}{l}\text { Plano Textual } \\
\text { Global }\end{array}$ & $\begin{array}{l}\text { INTRODUÇÃO: SEM } \\
\text { INTRODUÇÃO } \\
\text { DESENVOLVIMENTO: } \\
\text { Exposiçầ de uma } \\
\text { asserção negativa quanto } \\
\text { ao uso de gêneros } \\
\text { digitais no ensino em } \\
\text { função das condiçōes } \\
\text { existentes. } \\
\text { CONCLUSÃO: } \\
\text { apresentaça de uma } \\
\text { questâo sobre o que } \\
\text { fazer. }\end{array}$ & 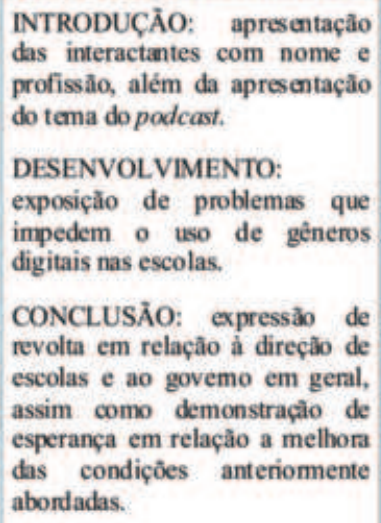 & $\begin{array}{lr}\text { Foram } & \text { feitas } \\
\text { adequações de } & \text { de } \\
\text { grandes proporçôes. }\end{array}$ \\
\hline $\begin{array}{l}\text { Tipos de } \\
\text { Discurso }\end{array}$ & $\begin{array}{l}\text { DISCURSO } \\
\text { INTERATIVO }\end{array}$ & DISCURSOINTERATIVO & \\
\hline $\begin{array}{l}\text { Tipos de } \\
\text { Sequência }\end{array}$ & EXPUICATIVA & DIALOGAL, EXPLICATIVA & \\
\hline
\end{tabular}

As adequações do podcast "Social Inclusion in Class", QUADRO 7, foram de grandes proporções por termos percebido grandes alterações, principalmente no conteúdo do arquivo. Observe que as modificações de nível organizacional são pequenas. 


\section{QUADRO 7 \\ SOCIAL INCLUSION IN CLASS}

\begin{tabular}{|c|c|c|c|}
\hline $\begin{array}{l}\text { SOCIAL } \\
\text { INCLUSION } \\
\text { IN CLASS }\end{array}$ & $I^{\text {I" versầ }}$ & $2^{a}$ versà̃o & Adequaçốes \\
\hline $\begin{array}{l}\text { Plano } \\
\text { Textual } \\
\text { Global }\end{array}$ & 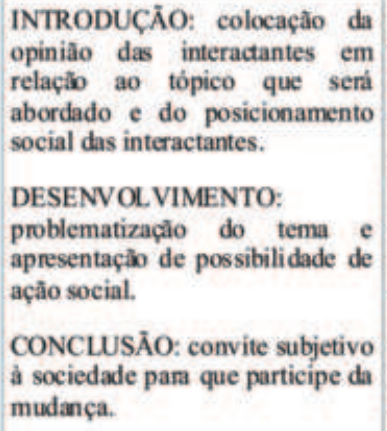 & 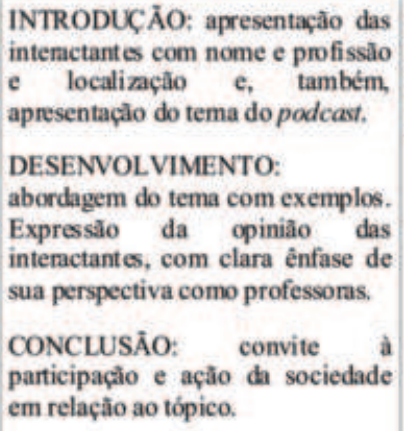 & $\begin{array}{l}\text { Foram feitas } \\
\text { adequaçốes } \\
\text { de grandes } \\
\text { proporçőes. }\end{array}$ \\
\hline $\begin{array}{l}\text { Tipos de } \\
\text { Discurso }\end{array}$ & DIRCUSO INTERATIVO & DISCURSO INTERATIVO & \\
\hline $\begin{array}{l}\text { Tipos de } \\
\text { Sequência }\end{array}$ & ARGUMENTATIVA & $\begin{array}{l}\text { DIALOGAL, } \\
\text { ARGUMENTATIVA }\end{array}$ & \\
\hline
\end{tabular}

No que tange aos aspectos relacionados à fonologia e à fluência, com base nas características elencadas por meio do Quadro Europeu Comum (2001), ouvimos cada um dos arquivos de segunda versão, fizemos a transcrição de cada um deles, procurando aplicar os aspectos fonológicos de "Connected Speech", cotejando com a análise também feita por uma professora visitante assistente, falante nativa de língua inglesa.

Classificamos os interactantes de acordo com a TAB. 5. É importante salientarmos que nós consideramos apenas inadequações severas de pronúncia, as quais poderiam prejudicar a inteligibilidade. 


\section{TABELA 5}

\begin{tabular}{|c|c|}
\hline Podcast & Classificacầo do Controle Fonológico \\
\hline "Blog - movie and literature" & $\begin{array}{l}\text { Interactante } 1-\mathrm{A} 2 \\
\text { Interactante } 2-\mathrm{A} 1 / \mathrm{A} 2\end{array}$ \\
\hline "Bullying in our society" & Interactante 1-A2 \\
\hline "How to overcome bullying?" & Interactante 1-B1 \\
\hline "Interview - English for basic education" & $\begin{array}{l}\text { Interactante 1-B1 } \\
\text { Interactante 2-A2 } \\
\text { Interactante } 3-\mathrm{B} 1\end{array}$ \\
\hline "The problem about teaching "digital genres" & Interactante $1-\mathrm{A}$ | \\
\hline Comum "Social Inclusion in class" & $\begin{array}{l}\text { Interactante } 1-\mathrm{A} 2 / \mathrm{B} 1 \\
\text { Interactante } 2-\mathrm{B} 2\end{array}$ \\
\hline "Using Blogs in Class" & $\begin{array}{l}\text { Interactante 1-B1 } \\
\text { Interactante 2-B1 }\end{array}$ \\
\hline
\end{tabular}

A fim de ilustrar, no arquivo "Blog - Movie and Literature" no qual as interactantes têm um problema de pronúncia com a palavra "Literature" (literatura). De acordo com o Cambridge Dictionaries Online, ${ }^{10}$ a transcrição da referida palavra seria: /' lit.ər.I.tfor/, enquanto que o som pronunciado pelas professoras se aproxima do seguinte: /'lit.ər.I.tu:r/. Consideramos esse aspecto como grave, pois esse é o tema principal da produção das professoras.

No caso da produção "Bullying in our society", a falta de ritmo como previsto pela prosódia prejudica a inteligibilidade, sendo que em alguns momentos ele se torna totalmente incompreensível.

Observamos que os professores estão entre os níveis A1 e B1, o que significa uma grande área de abrangência. Acreditamos que, para trabalhar como professores de LI, a maioria deles precisa trabalhar suas habilidades orais.

\subsection{A intervenção}

Para que pudéssemos analisar a relação entre a intervenção e o aprendizado dos professores em formação e, assim, justificar as modificações ocorridas, utilizamos a equiparação entre as capacidades de linguagem e as atividades desenvolvidas no "Módulo 2 - Have you ever podcasted? Pod what?" do livro "Connecting Ide@s” (2011), com base na apresentação feita por Anjos-Santos e Cristovão (2012). 
Nesta seção apresentamos a proposta didática para a mídia em foco, seguidos de comentários, relacionando modificações e intervenção. Apesar de aplicarmos as capacidades de linguagem em gêneros textuais e não considerarmos o podcast como um, entendemos que seu uso é, ainda assim, essencial, uma vez que elas poderão ser usadas como guia de efeito social, função, contexto, organização e língua do arquivo MP3 disponibilizado on-line.

Para cada uma das Capacidades de Linguagem, primeiramente, apresentamos a análise feita por Anjos-Santos e Cristovão e, em seguida, os comentários relacionados às produções.

Atividades Relacionadas às Capacidades de Linguagem

Capacidades de Significação:

"I - Listar gêneros, ação de linguagem e ação praxiológica propiciada por diferentes redes sociais.

II - Discutir os papéis e impactos da tecnologia e das redes sociais na contemporaneidade e no ensino de línguas"

De acordo com Cristovão e Stutz (2011), as capacidades de significação atuam como expressão da relação do sujeito com o mundo em suas muitas expressões (ideológicas, histórico, sócio-cultural etc.). Essa capacidade se faz importante para que as professoras em formação entendam a importância do uso de tecnologias de informação e comunicação (TDIC) em sala de aula e quais os possíveis reflexos de seu uso com os nativos digitais.

\section{Capacidades de Ação:}

"I - Navegar num perfil de podcast e responder perguntas sobre o contexto de produção (quem, quando, onde, para quem, como e por quê)

II - Ouvir um podcast e responder sobre seu conteúdo, as informações apresentadas e a relação com o contexto.

III - Discutir e refletir sobre a importância do contexto de produção.”

Esse é segundo nível de uso das capacidades. Após entendermos a importância e refletirmos sobre o objeto pensando nos reflexos sociais dele, pensamos agora em seu contexto de produção e sua importância. Por que é importante saber quem, onde, por que e como foi produzido tal podcast? Os parâmetros físicos e sociossubjetivos dos elementos que constituem o contexto nos auxilia na compreensão das bases ideológicas, culturais e de relações sociais do(s) enuciador(es) e seus interactantes pretendidos. 


\section{Capacidades Discursivas:}

"I - A partir de uma lista de elementos, identificar aqueles presentes no podcast ouvido.

II - Ouvir o podcast novamente e identificar como ele está organizado,

III - Assistir a um videocast e comparar as semelhanças e diferenças relacionadas à organização.

IV - Discutir e refletir sobre a importância da organização textual."

As capacidades discursivas serão essenciais no nível organizacional e são, indubitavelmente, razão de adaptações nos podcasts da primeira para a segunda versão. As atividades relacionadas a essa capacidade possibilitam mudanças como no exemplo comentado a seguir.

No podcast "presenting a Facebook profile", as professoras-produtoras produziram um arquivo que apenas introduzia o tema e não apresentava conclusão. Observe a transcrição a seguir (os nomes das professoras foram substituídos para preservarmos suas identidades):

CARMEN: ok, now we have on the profile of the Facebook, so a friend of us is going to present her profile.

BETH: Hello, my name is Beth. I was born in Londrina in February, 16th, 1959. I'm female. I live in Londrina, I was born in Londrina. I'm interested in family friends and work. I speak Portuguese and English. I studied Letras at UEL and I'm an English teacher, I teach for kids. I work at (.).

Contudo, na segunda versão após a intervenção, elas preparam um podcast com introdução, incluindo apresentação dos interactantes e do tema, desenvolvimento e conclusão, mostrando para o leitor um começo, meio e fim; característica importante elencada por Carvalho et. al. (2008).

Capacidades linguístico-discursivas:

"I - Ouvir outro podcast e colocar suas partes em ordem.

II - Completar com marcadores pragmáticos a transcrição do podcast.

III - Discutir a função dos marcadores pragmáticos em podcasts.

IV - Discutir e refletir sobre a importância dos recursos linguísticos na produção textual.

V - Praticar pronúncia e entonação em língua inglesa."

As capacidades linguístico-discursivas são aquelas relacionadas aos aspectos léxico-gramaticais e fonológicos da língua. Elas se justificam, pois possi- 
bilitam a expressão e compreensão entre interactantes. Quando essa capacidade não é devidamente trabalhada, o texto torna-se linguisticamente pobre, impossibilitando o contato entre os falantes.

Infelizmente, essa foi uma das capacidades que não atingiram seu objetivo, uma vez que o nível de proficiência dos professores deixou a desejar na maior parte dos podcasts, chegando a prejudicar a sua compreensão e transcrição em alguns casos, como no exemplo abaixo:

Bullying in our society

PAM: nowadays the bullying is the polemic topic in our society because people are prejudiced discriminate someone who is different; can be fat or short, your color and so on. For this reason we need about that contributing in this way for more respect with other people.

\section{Considerações Finais}

Lembrando que nosso objetivo principal era investigar a aprendizagem da mídia digital podcast por professores em formação continuada durante um curso para inovação tecnológica, através da descrição das produções, assim como verificação de adequação entre as características da mídia e as produções, consideramos tê-lo atingido. As análises demonstraram que as produções apresentaram características conforme a literatura especializada, bem como sofreram adequações entre as versões inicial e final. Também pudemos pontuar a relevância de uns dos instrumentos de mediação usados, o material Connecting Ide@s. As atividades desenvolvidas, as interações propostas, as reflexões trazidas à tona foram deflagradas a partir das proposições do material. Vale ressaltar que o material fora objeto de análise dos autores / produtores e também sofreu alterações para sua segunda edição.

Assim, consideramos que a intervenção teve efeito positivo nos professores, uma vez que, durante a descrição, observamos que as adequações em todos os arquivos tinham relação com o conteúdo explorado no curso. No entanto, apesar de destacarmos que o uso do material "Connecting Ide@s” foi essencial durante a intervenção, realçamos que seria preciso um trabalho com mais enfoque em habilidades orais quando a ênfase for uma mídia ou gênero primordialmente oral.

Esperamos que os professores participantes possam servir-se dessa mídia como um recurso para o ensino de inglês com diversos propósitos, con- 
forme discutido anteriormente. Em disseminações orais desse trabalho, outros professores questionaram justamente se o podcast passará a ser uma ferramenta de mediação nas salas de aula dos participantes, questão que pode ser objeto de uma próxima pesquisa.

\section{Notas}

${ }^{1}$ Este trabalho está inserido no projeto de pesquisa "O uso de podcast na educação continuada de professores de língua inglesa", coordenado pela co-autora desse trabalho. Agradecemos à Fundação Araucária, convênio 09/2010, pela bolsa de produtividade de pesquisa à coautora, no período maio/2011 a abril/2012, e ao CNPq, pela bolsa de Iniciação Científica ao primeiro autor.

${ }^{2}$ Vinícius Neves de Cabral foi aluno do Programa de Iniciação Científica com bolsa da Fundação Araucária no período de agosto/ 2011 a julho/2012. Atualmente, cursa o 30 ano de Letras Estrangeiras Modernas - Inglês, na Universidade Estadual de Londrina. É professor em uma escola de idiomas de Londrina.

${ }^{3}$ Para melhor compreensão do projeto conferir: EL KADRI, M. S.; GAMERO, R., GIMENEZ, T. N. Material didático para educação tecnológica de professores de inglês: uma experiência no âmbito do programa 'novos talentos'. Linguagem \& Ensino, Pelotas, v. 15, n. 1, p. 181-212, jan./jun.2012. Disponível em:

$<$ http://revistas.ucpel.tche.br/index.php/rle/article/view/483>. Acesso em: 31 ago. 2012.

${ }^{4}<$ http://www.nytimes.com/pages/podcasts/index.html?8qa $>$

$5<\mathrm{http}: / /$ www.bbc.co.uk/podcasts $>$

${ }^{6}<\mathrm{http}: / /$ www.dw.de/dw/0,95541,00.html $>$

${ }^{7}$ Teachers of English need to understand the implications of the unprecedented spread of the language and the complex decisions they will be required to take.

${ }^{8}$ Disponível em:

$<$ http://www.bbc.co.uk/worldservice/learningenglish/grammar/pron/features/connected.shtml>

${ }^{9}$ Disponível em: $<$ http://www.podomatic.com/login $>$

${ }^{10}$ Disponível em: $<$ http://dictionary.cambridge.org/dictionary/british/literature_1?q=literature> 


\section{Referências}

ADAM, J-M. Les textes: types et prototypes. Paris, Nathan. 1992.

ANJOS-SANTOS, L. M.; CRISTOVÃO, V. L. L. Educação Continuada de Professores e Uso de Tecnologias Digitais de Informação e Comunicação: uma análise a partir da mediação formativa com Podcasts. CONGRESSO INTERNACIONAL DA ABRAPUI, 3, 2012, Florianópolis. Comunicação oral. Florianópolis, Universidade Federal de Santa Catarina, 2012.

ARAÚJO, A. D. “Crenças e concepções do professor-educador sobre a formação do professor de língua estrangeira. In: GIMENEZ, T. (Org.). Ensinando e aprendendo inglês na universidade: Formação de professores em tempos de mudança. Londrina, ABRAPUI, 2003, p. 85-94.

BAKER, W. The Cultures of English as a Lingua Franca. TESOL QUARTERLY, v.. 43, n. 4, p. 567-592, December 2009..

BAKHTIN, M. M. Estética da criação verbal. 2. ed. São Paulo: Martins Fontes. 1997.

BONINI, A. Midia/suporte e hipergênero: os gêneros textuais e suas relações. RBLA, Belo Horizonte, v. 11, n. 3, p. 679-704, 2011.

BRAGA, D. B. Tecnologia e participação social no processo e consumo de bens culturais: novas possibilidades trazidas pelas práticas letradas digitais mediadas pela internet. Trabalhos em Linguística Aplicada, Campinas, v. 49, nº 2, p. 373-391, 2010.

BRONCKART, J.-P. Atividade de Linguagem, textos e discursos: por um Interacionismo sociodiscursivo. Trad. Anna Rachel Machado, Péricles Cunha - 2.ed., 1. Reimpr. São Paulo: Educ, 2009.

BRONCKART, J.-P. O agir nos discursos: das concepções teóricas às concepções dos trabalhadores. Trad. Ana Raquel Machado, Maria de Lourdes Meirelles Matêncio. Campinas, SP: Mercado de Letras, 2008.

BRONCKART, J.-P. Atividade de Linguagem, discurso e desenvolvimento humano./JeanPaul Bronckart. (Anna Rachel Machado e Maria de Lourdes Meirelles Matencio (Org.); Trad. Anna Rachel Machado e Maria de Lourdes Meirelles Matencio et. al. Campinas, SP: Mercado de Letras, 2006. (Série Ideias sobre Linguagem).

BROWN, J. D. Promoting fluency in EFL classrooms. ANNUAL JALT PAN-SIG CONFERENCE, 2, May 10-11, 2003. Kyoto, Japan. Proceedings ... Kyoto Institute of Technology. Disponível em: <http://www.jalt.org/pansig/2003/HTML/Brown.htm> Acesso em: 28 ago. 2012.

CAMERON, D. Globalization and the teaching of 'communication skills'. In: BLOCK, D.; CAMERON, D. Globalization and language teaching. London and New York, 2002, p 69-82.

CARVAlHO, A. A. et al. Taxonomia de Podcasts. Disponível em: <http://www.iep.uminho.pt/podcast/Taxonomia_Podcasts.pdf $>$. Acesso em: nov. 2010.

CONSELHO DA EUROPA. Quadro europeu comum de referência para línguas: aprendizagem, ensino, avaliação. Porto, Portugal: Edições ASA, 2001. 
CRISTOVÃO, V. L. L; STUTZ, L. Sequências Didáticas: semelhanças e especificidades no contexto francófono como L1 e no contexto brasileiro como LE. In: SZUNDY, P. T. C. et al. (Org.). Linguística Aplicada e Sociedade: ensino e aprendizagem de línguas no contexto brasileiro. Campinas: Pontes Editores, 2011, v. 1, p. 17-40.

DEVITT, A. Teaching Critical Genre Awareness. In: BAZERMAN, Charles; BONINI, Adair; FIGUEIREDO, Débora (Ed.). Genre in a Changing World. Perspectives on Writing. Fort Collins, Colorado: The WAC Clearinghouse and Parlor Press, 2009. Disponível em: <http://wac.colostate.edu/books/genre/chapter17.pdf>. Acesso em: jun. 2012.

DOLZ, J; SCHNEUWLY, B. Gêneros orais e escritos na escola. Campinas: Mercado de Letras, 2004.

EL KADRI, M. S., GAMERO, R., GIMENEZ, T. N. Material didático para educação tecnológica de professores de inglês: uma experiência no âmbito do programa 'novos talentos' In: Linguagem \& Ensino, Pelotas, v. 15, n. 1, p. 181-212, jan./jun.2012. Disponível em: $<$ http://revistas.ucpel.tche.br/index.php/rle/article/view/483>. Acesso em: 31 ago. 2012.

FERREIRA, Anise D'Orange. Considerações sobre o contexto digital do trabalho docente com tecnologias digitais. In: MACHADO, A. R.; LOUSADA, E. G.; FERREIRA, A. D. (Org.). O professor e seu trabalho: a linguagem revelando práticas docentes. Campinas, SP: Mercado de Letras, 2011, p. 29-60.

GODWIN-JONES, R. Skype and Podcasting: Disruptive Technologies for Language Learning. Language Learning \& Technology. v.. 9, n. 3, p. 9-12, 2005. Disponível em: $<$ http://lt.msu.edu/vol9num3/emerging/default.html $>$. Acesso em: nov. 2010.

FILLMORE, C. J. . On fluency. In C. J. Fillmore, D. Kempler, \& W. S. Y. Wang (Eds.), Individual differences in language ability and language behavior . New York: Academic Press. 1979, p. 85-102.

HALLIDAY, M. A. K. An introduction to functional grammar. 3 ed. UK, 2004.

HEBERLE, V. M. 30 years of EFL teaching in Brazil: glimpses of past realities and prospects for the future. In: GIMENEZ, T. (Org.). Ensinando e aprendendo inglês na universidade: Formação de professores em tempos de mudança. Londrina, ABRAPUI, 2003, p. 47-52. HENTZ, M.I. B. O espaço dos gêneros do discurso na formação continuada de professores. In: ENCONTRO DO CELSUL, 5, 2003, Curitiba. Anais... Curitiba, Universidade Federal do Paraná, 2003, p. 970-979.

JENKINS, J. Which pronuncitation norms and models for English as an International Language?, ELT Journal, v. 53, n. 2, p. 119-126, 1998.

JENKINS, J. Current perspectives on teaching World English and English as a lingua franca. TESOL Quarterly, v. 40, n. 1, 2006.

JENKINS, J. English as a Lingua Franca. Oxford: Oxford University Press, 2007.

LEFFA, V. J. Aspectos políticos da formação do professor de línguas estrangeiras. In: LEFFA, Vilson J. (Org.). O professor de línguas estrangeiras; construindo a profissão. Pelotas, 2001, v. 1, p. 333-335. Disponível em: http://www.leffa.pro.br/textos/trabalhos/formacao.pdf 
LLURDA, E. Non-native-speaker teachers and English as an International Language. International Journal of Applied Linguistics, v. 14, n. 3, p. 314-323, 2004.

MACHADO, A. R. A perspectiva interacionista sociodiscursiva de Bronckart. In: Gêneros: teorias, métodos e debates. São Paulo: Parábola Editorial, 2005. P. 237-259. MARCUSCHI, L. A.. Produção Textual, Análise de Gêneros e Compreensão. São Paulo: Parábola Editorial, 2008.

MEDEIROS, M. S. Podcasting: um antípoda radiofônico. ENCONTRO DOS NÚCLEOS DE PESQUISA DA INTERCOM, 6, 2006. Anais... Brasília, Universidade de Brasília, UnB, 2006.

MEDRADO, B. P. Fotografias da sala de aula: relato de experiências sob uma perspectiva reflexiva. In: GIMENEZ, T. (Org.). Ensinando e aprendendo inglês na universidade: Formação de professores em tempos de mudança. Londrina, ABRAPUI, 2003, p. 95-102.

MOITA-LOPES, L. P. da. A formação teórico-crítica do professor de línguas: o professor-pesquisador. In: . Oficina de Linguística Aplicada. São Paulo: Mercado das Letras, 1996. P. 179-190.

MOURA, A.; CARVALHO, A. (2006). Podcast: uma ferramenta para usar dentro e fora da sala de aula. In: RUI, José; BAQUERO, C. (Ed.). Conference on Mobile and Ubiquitous Systems (CSMU 2006). Universidade do Minho, Braga, 155-158, 2006.

PRENSKY, M. Don't bother me, Mom, I'm learning!: how computer and video games are preparing your kids for the $21^{\text {st }}$ century success and how you can help!. US: Paragon House, 2006.

RAJAGOPALAN, K. Por uma linguística crítica: linguagem, identidade e a questão ética. São Paulo: Parábola Editorial; 2003.

RIOS-REGISTRO, E. S. et al. Connecting Ide@s: tools for teaching English in a contemporary society. Londrina: UEL, 2011.

SIFAKIS, N. The education of teachers of English as a lingua franca: a transformative perspective. International Journal of Applied Linguistics, v. 17, n. 3, p. 355-375, 2007.

SAMPAIO, L. Banda larga móvel cresce 590\% em apenas dois anos e meio. Folha de São Paulo, São Paulo, 28 de agosto de 2012. Disponível em: $<$ http://www1.folha.uol.com.br/mercado/1142287-banda-larga-movel-cresce-590-emapenas-dois-anos-e-meio.shtml > . Acesso em: 31 ago. 2012.

SCHMITZ, J. R. To ELF or not to ELF? English as a Lingua Franca): That's the question for Applied Linguistics in a globalized world. Revista Brasileira de Linguística Aplicada, v. 12 , n. 2, p. 249-284,2012.

SEIDLHOFER, B. Research perspectives on teaching English as a lingua franca. Annual Review of Applied Linguistics, v. 24, p. 209-239, 2004.

SOUZA, S. A.; MARTINS, C. B. M. J.Exemplos de usos do podcasting no ensino de línguas estrangeiras. In: ENCONTRO DE PROFESSORES DE LÍNGUAS ESTRANGEIRAS DO PARANÁ, 15, 2007, Curitiba. Anais... Curitiba, PR: Gráfica e Editora Lastro, 2007. p. 220-228. Disponível em: <http://www.apliepar.com.br/site/anais_eple2007/artigos/19_shirley.pdf> 
UCHÔA, J. M. S. O gênero Podcast educacional: descrição do conteúdo temático, estilo e construção composicional. Dissertação de Mestrado - Universidade Federal do Acre). Acre, 2010.

Data de submissão: 30/11/2012

Data de aprovação: 01/02/2013 